\title{
INFLUENCE OF DIET FORTIFICATION ON BODY COMPOSITION AND APPARENT DIGESTION IN MATURE HORSES CONSUMING LOW-QUALITY FORAGE
}

\author{
A Thesis \\ by \\ MATTEA LEE MUCH \\ Submitted to the Office of Graduate and Professional Studies of \\ Texas A\&M University \\ in partial fulfillment of the requirements for the degree of \\ MASTER OF SCIENCE \\ Tryon A. Wickersham
}

Chair of Committee, Jessica L. Leatherwood

Committee Members, James D. Herman

Head of Department, Cliff Lamb

May 2019

Major Subject: Animal Science

Copyright 2019 Mattea Lee Much 


\section{ABSTRACT}

Quarter Horse mares $(498 \pm 9 \mathrm{~kg} \mathrm{BW} ; 12 \pm 7 \mathrm{yr})$ were utilized in a completely randomized design for $56 \mathrm{~d}$ to test the hypothesis that concentrate fortification improves apparent digestibility and enhances lean mass over the topline. Horses were stratified by age, BW, and BCS and randomly assigned to either a custom pelleted concentrate (CON; $n=13)$, or an isocaloric, iso-nitrogenous pellet that included amino acid fortification, complexed trace minerals, and fermentation metabolite fortification (FORT; $\mathrm{n}=10$ ). Concentrate was offered at a total $0.75 \% \mathrm{BW} / \mathrm{d}$ (as-fed) in twice daily rations, and diets were designed to meet or slightly exceed maintenance requirements for mature horses. Horses had ad libitum access to Coastal Bermudagrass hay $(7.4 \% \mathrm{CP}, 67 \% \mathrm{NDF}$, and $40 \%$ ADF). Every $14 \mathrm{~d}$, BW and BCS were recorded and ultrasound images were captured every $28 \mathrm{~d}$. Longissimus dorsi area (LDA) and subcutaneous fat thickness (FT) were measured between the 12 and $13^{\text {th }}$ ribs (12/13) and 17 and $18^{\text {th }}$ ribs (17/18). Intramuscular fat at 17/18 and rump-fat thickness were also obtained. Horses were dosed with $10 \mathrm{~g} / \mathrm{d}$ of titanium dioxide $\left(\mathrm{TiO}_{2}\right)$ for $14 \mathrm{~d}$ to estimate forage dry matter intake (DMI). To account for diurnal variation, fecal samples were collected twice daily at $12 \mathrm{~h}$ intervals during the last four days, advancing by $3 \mathrm{~h}$ each day to represent a $24 \mathrm{~h}$ period. Fecal samples were composited by horse and analyzed for $\mathrm{TiO}_{2}$ to estimate fecal output and acid detergent insoluble ash was used to calculate forage DMI. To evaluate body composition, horses were infused with a $0.12 \mathrm{~g} / \mathrm{kg} \mathrm{BW}$ deuterium oxide $\left(\mathrm{D}_{2} \mathrm{O}\right)$ on $\mathrm{d} 0$ and 56 . Body fat percentage (BF) was determined by quantifying $\mathrm{D}_{2} \mathrm{O}$ in plasma samples collected at pre- and 4-h postinfusion via mass spectrometry. All data were analyzed using PROC MIXED (SAS v9.4). The model contained a fixed effect of diet; horse (diet) was a random effect. Horses receiving FORT 
gained 17/18 FT $(P<0.01)$ and increased 17/18 LDA from $\mathrm{d} 0$ to $56(P<0.01)$ while $17 / 18 \mathrm{FT}$ and LDA were unchanged in CON. Regardless of diet, BF calculated by $\mathrm{D}_{2} \mathrm{O}$ infusion increased in all horses from d 0 to $56(P<0.01)$. Average hay DMI was $2.1 \% \mathrm{BW}$, but did not differ between diets. In this study, concentrate fortification did not significantly $(P \geq 0.27)$ affect apparent digestion. In conclusion, feeding a fortified concentrate may promote greater muscle development along the posterior topline, and the use of ultrasonography may provide a more objective assessment of body composition when compared to tactile body condition assessment in mature horses. 


\section{DEDICATION}

For my folks. 


\section{ACKNOWLEDGEMENTS}

I would like to express my tremendous gratitude to my committee chair, Dr. Jessica Leatherwood, for her unwavering support, patience, and positive attitude throughout my graduate career. I would also like to thank my committee members and advisors, Dr. Tryon Wickersham, Dr. James Herman, and Dr. Jennifer Zoller. In addition, Mr. Bob Byrns at Parsons Mounted Cavalry has supported me throughout this program in too many ways to count. Without him, I would not be where I am today. Lastly, thank you to my fellow graduate student colleagues and undergraduate student research assistants. Without them, running a project of this magnitude would not be possible. 


\section{CONTRIBUTORS AND FUNDING SOURCES}

This work was supervised by the principal investigator, Dr. Jessica Leatherwood, committee member, Dr. Tryon Wickersham, and collaborator, Dr. Jennifer Zoller, in the Texas A\&M Department of Animal Science.

This study was conducted with funding provided by Cargill Inc. and the authors affirmatively acknowledge that they were free from influence by Cargill Inc. and its employees that would result in any conflict of interest. 


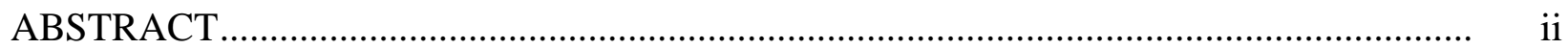

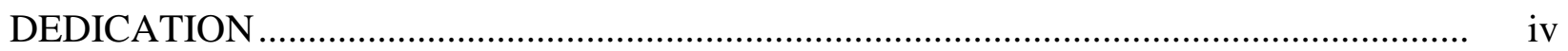

ACKNOWLEDGEMENTS ....................................................................................

CONTRIBUTORS AND FUNDING SOURCES ……..................................................... vi

TABLE OF CONTENTS ............................................................................................... vii

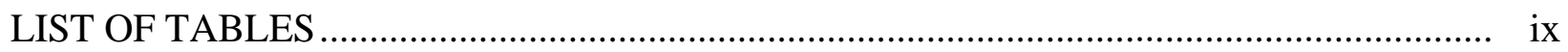

CHAPTER I INTRODUCTION AND REVIEW OF THE LITERATURE........................ 1

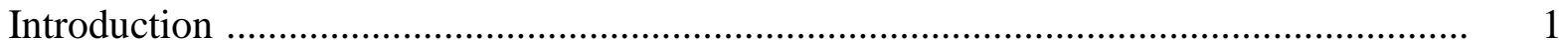

Nutrient Absorption ............................................................................................... 2

Apparent Digestion Techniques..................................................................................... 8

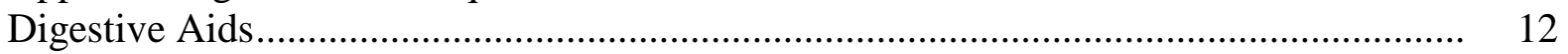

Body Composition ................................................................................................... 13

Deuterium Oxide......................................................................................... 16

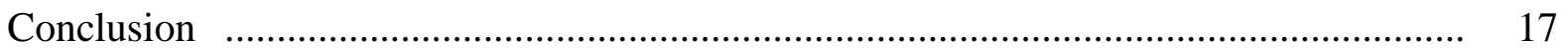

CHAPTER II $\quad$ MATERIALS AND METHODS ………................................................ 18

Horses and Dietary Treatments............................................................................... 18

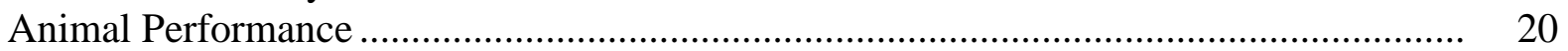

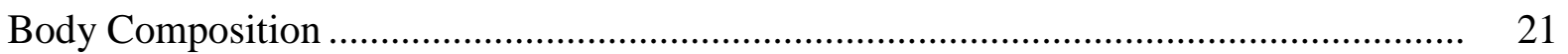

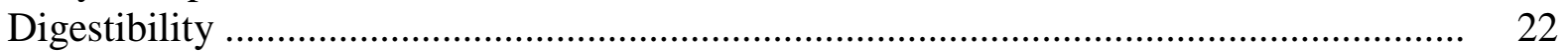

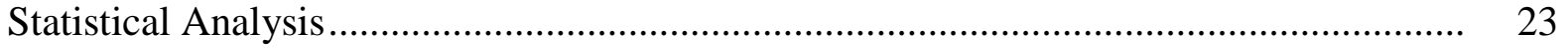

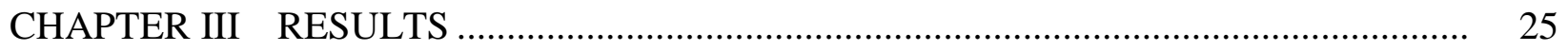

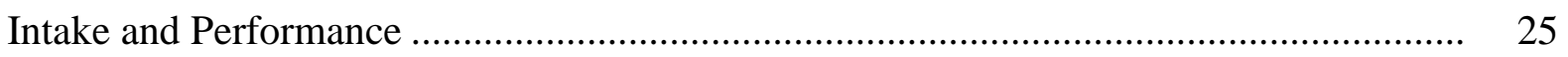

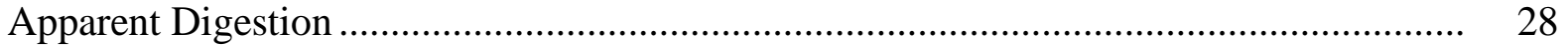

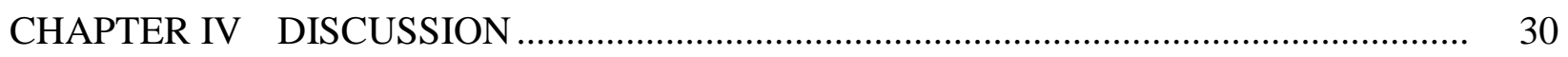

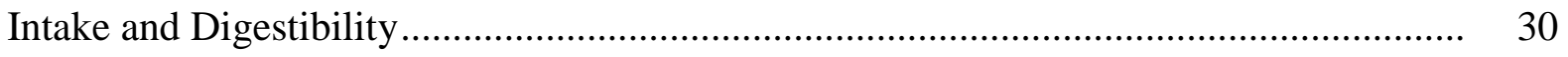

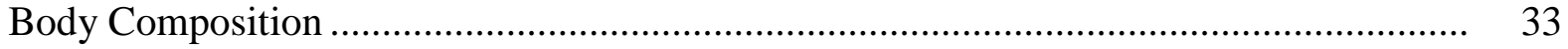




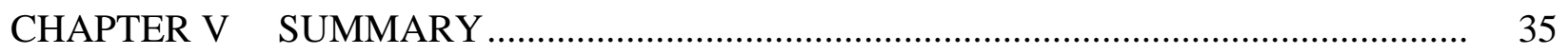

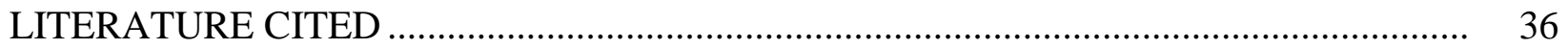




\section{LIST OF TABLES}

\section{Page}

Table 1 Energy and nutrient composition of pelleted concentrate and coastal Bermudagrass (Cynodon dactylon) hay fed to stock-type mares

Table 2 Amino acid composition of the control (CON) pellet and fortified (FORT) pellet that contained an additional amino acid pack, fermentation metabolite additives, and complexed trace minerals concentrate offered at $0.75 \% \mathrm{BW}$ (as-fed basis).

Table 3 Dry matter intake (DMI) of control (CON) or iso-caloric, iso-nitrogenous fortified (FORT) pelleted concentrate and coastal Bermudagrass (Cynodon dactylon) fed to stock-type mares (least square means).

Table 4 Mean change of ultrasonography measurements ( \pm SEM) of fat thickness (FT) and longissimus dorsi area (LDA) over the $12^{\text {th }} / 13^{\text {th }}$ and $17^{\text {th }} / 18^{\text {th }}$ ribs and intramuscular fat (IMF) in response to feeding either a CON or FORT pelleted concentrate and coastal Bermudagrass.

Table 5 Mean BW ( \pm SEM) and BCS change in response to feeding either a CON or FORT pelleted concentrate and coastal Bermudagrass.

Table 6 Apparent digestion of nutrients in response to feeding either a CON or FORT pelleted concentrate and coastal Bermudagrass. 


\section{CHAPTER I}

\section{INTRODUCTION AND REVIEW OF THE LITERATURE}

\section{Introduction}

Forage is a primary component of the equine diet; however, a challenge equine managers often face is variability in both quality and consistency in available stored forages. Adding lactic acid-producing bacteria (Lactobacillus, Bifidobacterium, and Enterococcus) to a diet has benefited the horse by improving digestion of minerals (Swyers et al., 2008) and tends to improve NDF and ADF digestion (Coverdale et al., 2013). When low-quality (LQ) forage (8.1\% $\mathrm{CP}, 75.3 \% \mathrm{NDF}$, and 37.6\% ADF) was offered, Morgan and associates (2007) determined the dietary fermentation aid Saccharomyces cerevisiae enhanced digestion of DM, CP, and NDF. Despite increasing microbial utilization of forage through the use of dietary fermentation aids, LQ forages may not provide adequate nutrients to meet the nutrient demands of the horse. Therefore, commercially formulated concentrates are used to offset this deficit by supplying additional nutrients not present in the forage that promote maintenance of muscle tissue and fat coverage in the horse.

Monitoring body composition is necessary to understand change in condition and health status. On a scale of 1-9, horse owners often strive to keep their horses at a body condition score of 5 to 6 to maximize athletic performance and reproductive efficiency (Henneke et al., 1983; Cavinder et al., 2009; Garlinghouse et al., 2010). Kubiak et al. (1987) determined mares with a $\mathrm{BF}$ of 11.5 to $15 \%$ cycled faster and conceived more readily than mares with less BF. Ultrasonography is used to monitor changes in tissue development and composition, as well as provide an estimation of BF using rump fat measurements (Westervelt et al., 1976). This 
equation assumes a specific location over the rump represents the individual's whole BF, but fails to account for intramuscular fat and variance in regional adiposity between horses of different breeds and ages. Additionally, the equation also indicates that a horse with no rump fat would still have $8.64 \% \mathrm{BF}$. Infusion of the stable isotope deuterium oxide and analysis of plasma pre- and post-infusion can provide a more comprehensive measurement of BF in equines (Dugdale et al., 2011; Ferjak et al., 2017).

Limited information has been gathered to compare performance and digestibility characteristics of mature horses maintained on LQ forage. Therefore, the objective of the current study was to determine the effect of diet fortification on apparent digestion and body composition in mature horses consuming a LQ forage.

\section{Nutrient Absorption}

Digestion of nutrients has long been studied to evaluate economic efficiency and usefulness of particular feeds in animals. Data gathered from this area of research is utilized in feed processing for food animal development so that maximum gain relative to the cost of input can be achieved. Since horses in the United States are not harvested as a source of protein, the traditional application of digestibility studies tends to cover a broader spectrum. In addition to the focus placed on early growth and development, the equine industry attends to other challenges such as maintaining body condition despite intense exercise or ageing. Rate of passage through an equine digestive tract is more rapid than in a ruminant because there is only one site of fermentative digestion, and consequently, apparent digestion of fiber is lower for a horse (Orton et al., 1985). Compared to cattle, horses have a higher rate of intake of forage, which compensates for the more rapid passage of nutrients (Duncan et al., 1990). The anatomical arrangement of an enzymatically rich foregut preceding a fermentative hindgut provides only a 
singular opportunity for production and utilization of volatile fatty acids, thus limiting the horse's ability to derive energy from roughage.

In a mature stock-type horse, the small intestine comprises one-third of the total volume and 10-12 feet of the digestive tract. The small intestine maintains a temperature of $39^{\circ} \mathrm{C}$ (Merritt and Julliand, 2013) and can be divided into three segments: duodenum, jejunum, and ileum. Due to bicarbonate secretion throughout the small intestine, $\mathrm{pH}$ increases from 6.3, to 7.1, to 7.3 (de Fombelle et al., 2003). Digestive enzymes are released into the duodenum through the sphincter of Oddi. Absorption of starch and protein substrates primarily occurs in the jejunum, and to a much lesser extent in the ileum. Equids are unable to derive energy from structural carbohydrates in the foregut due to the lack of cellulase and other enzymes that degrade structures such as cellulose, hemicellulose, and pectin found in plant cell walls.

Enterocytes are the primary cell found in the small intestine. This cell is responsible for transportation of dietary nutrients from the lumen of the small intestine into the bloodstream of the animal. The gut provides a tremendous amount of surface area for the animal's body to interact with externally acquired digesta, and must protect the animal from absorbing toxic substances while ensuring sufficient intake of energy-producing substrates. Surface area, and therefore absorptive efficiency, is increased by undulations in the tissue as well as villi and microvilli. Micronutrients become trapped in the glycocalyx, a sticky region encompassing the microvilli, and must then be transported across the cell's membrane. When nutrients leave the lumen of the small intestine, they must cross the apical membrane of the small intestine via passive diffusion, facilitated diffusion, or active transport. Several nutrient-specific transporters line the basolateral membrane of the enterocytes, regulating absorption of nutrients into the 
blood, where they are transported to the liver to either be stored later for energy, or utilized to maintain cellular function.

Non-structural carbohydrates may enter the equine enterocyte through several modes. By expending 1 ATP molecule, the sodium-potassium pump on the basolateral membrane transports 2 potassium ions intracellularly and 3 sodium ions extracellularly, creating a gradient for the influx of sodium ions from the cell's apical membrane (lumen). A sodium ion is transported into the cell via a co-transporter, Sodium Glucose Linked Transporter 1 (SGLT1) along with glucose and galactose molecules. In addition, GLUT5 serves as a facilitator for the diffusion of fructose into the enterocyte. Similarly, GLUT2 permits entry of glucose, galactose, and fructose into the cell, but has the ability to translocate from the apical to the basolateral membrane, and also facilitates the transport of these monosaccharides into the bloodstream (Leturque et al., 2009). Protein digestion begins in the stomach when the structure dissociates in the presence of hydrochloric acid and pepsin. In the small intestinal lumen, dipeptides and tripeptides enter the enterocyte with aid from the $\mathrm{PEPT}_{1}$ cotransporter. Furthermore, free amino acids can cross the apical membrane through either a sodium-independent or sodium-dependent transporter. Again, the sodium-potassium pump on the basolateral membrane creates a gradient. A sodium proton pump allows one sodium ion to enter the cell on the apical membrane in exchange for a proton; sodium may also enter the enterocyte along with a free amino acid in the sodium-dependent transporter. Once inside the cell, oligopeptides are further dissociated by peptidases, from which free amino acids transaminate and pass through the liver-either contributing toward muscle development, provide energy post-deamination, or exit the body via excreted ammonia. Undigested protein that passes into the cecum is not utilized as a major source of energy in the horse. Unlike ruminants, which can produce microbial crude protein (MCP) pre-gastrically in the 
rumen, microbes in the horse synthesize MCP post-gastrically. As protein is further degraded by microbes, the carbon skeleton Thus, a surplus of protein in the diet is not utilized by the horse.

Lipids, or triacylcglycerol (TAG), are primarily absorbed in the jejunum of the small intestine. Pancreatic lipase, colipase, and bile salts emulsify fat molecules to create a larger surface area for digestion. In most monogastrics, bile is stored in the gall bladder and secreted in stimulus to the presence of chyme in the duodenum. Horses lack a gall bladder, however, and continuously secrete bile. This evolutionary adaption may be attributed to the horse's continuous grazing behavior, and in addition to the relatively low fat content in a forage-only diet. In the lumen, monoacylglycerol (MAG), diacylglycerol, and lysophospholipids form a mixed micelle, surrounding cholesterol, fat-soluble vitamins (A, D, E, and K), and non-esterified fatty acids (NEFAs) to be transported and held in the brush border. Monoacylglycerol and phospholipids enter the enterocyte through passive diffusion, while cholesterol and SCFAs enter through a protein-dependent mechanism (Wu 2018). Long chain fatty acids are believed to enter via either mechanism. A recent study has proposed mTORC1/2 regulates triglyceride absorption (BatistaGonzalez t al., 2018), but a complete understanding of transporters involved in uptake is limited (Mansbach \& Gorelick, 2007). Once inside the cell, MAGs are re-esterified using acyl CoA synthetase to form TAGs. Inside the endoplasmic reticulum, the apoprotein B48, TAGs, cholesterol, and phospholipids assemble to form a chylomicron. In the Golgi apparatus, the chylomicron is further stabilized and coated with carbohydrates. Small chain fatty acids cross the basolateral membrane and enter the blood stream to be transported to the liver, while medium chain and long chain fatty acids are exocytosed into the lymphatic system.

Post-ileum, the remainder of the equine digestive tract is referred to as the hindgut. Termed the 'microbiome', the hindgut is inhabited by bacteria, anaerobic fungi, and protozoa 
that aid in fermenting the digesta. Energy is obtained from non-structural carbohydrates by digesting the leaf and stem components of roughage to form volatile short chain fatty acids (VFAs). The three main VFAs in the hindgut are acetate, propionate, and butyrate. In horses maintained on a 100\% timothy hay diet, the molar percentage of VFAs in the cecum were: $76 \%$ acetate, $14 \%$ propionate, $8 \%$ butyrate, and $2 \%$ other (Hintz et al., 1971). In the same experiment, horses maintained on a 1:4 forage: grain diet of timothy hay and shelled corn observed the following VFA ratio in the cecum: $61 \%$ acetate, $26 \%$ propionate, and $8 \%$ butyrate. Within the cecum, acetate is seen in greatest proportion (NRC 2007), directly contributing to energy production. Acetate may also be converted into long chain fatty acids (LCFAs) to be stored as triglycerides or be utilized in the milk of lactating mares (NRC, 2007). Doreau et al. (1992) reported that a $95 \%$ forage ration compared to a $50 \%$ forage and $50 \%$ grain ration yielded a higher fat content in mare's milk during the first 2 weeks of lactation. Propionate is also a significant source of energy from the large intestine. Simmons and Ford (1991) estimated that over half of glucose in circulation from ponies consuming a forage-only diet originated from propionate. Butyrate is a significant energy source for the colonocytes, and has been associated with decreasing the incidence of colon cancer (Hamer et al., 2007). Lactate is another VFA that can be found in the large intestine, although it is less common than the other three in healthy horses. Lactate significantly increases in the cecal contents when high starch meals are consumed. Horses consuming 2 to 4 grams of starch per meal for each kilogram of bodyweight are at risk of developing a condition known as 'starch overload', which may contribute to laminitis or profound gas colic in the hindgut.

Starch is known to have high uptake in the digestive tract. It takes the form of an $\alpha$-Dglucose structure. Horses can absorb a maximum of 3.5 to $4 \mathrm{~g}$ starch/ $\mathrm{kg}$ bodyweight (BW) in the 
small intestines, with excess undergoing rapid fermentation by bacteria in the cecum (Potter et al., 1992). When starch bypasses the small intestines, it undergoes rapid fermentation in the cecum, which will lead to 'starch overload', laminitis, and potentially colic. It is recommended that horses be limited to less than $2 \mathrm{~g}$ starch/ kg BW to avoid these conditions (Hoffman, 2013).

Protein, in comparison to starch, has reduced absorption in the digestive tract. Studies evaluating CP digestibility from coastal Bermudagrass hay have found an absorption rate of 4252\% (Fonnesbeck 1967; Gibbs 1982; Aiken et al., 1989). Since protein is the most expensive nutrient, finding a balance between maximizing usability while minimizing waste is a large concern among horse owners. Furthermore, quality protein must be provided in a bioavailable form for the horse to utilize it. Essential amino acids are required in the diet because the animal is unable to synthesize them to meet requirements. To replenish protein turnover, these amino acids must be provided in specific quantities to optimize growth. For example, lysine is known as the 'first limiting amino acid'; its requirement is greatest in the horse's diet. If lysine is provided inadequately, the excess of other amino acids will be oxidized into waste products so that their ratio rebalances to match the quantity of lysine provided ( $\mathrm{Wu} 2018$ ).

Apparent digestibility is calculated by [intake-feces output]/intake. (Frape 2010). This does not take into account endogenous sources of protein that arise from enterocytes, which results in an underestimation of true digestibility by as much as $25-30 \%$ (Wu 2013). True digestibility is the most accurate assessment because it accounts for endogenous nutrient interference; however, studies of this nature are limited in the horse. Minimal absorption occurs in the distal ileum, which makes this location ideal for the placement of a cannula to sample intestinal flux. If a true digestibility study is conducted, baseline endogenous flow of free amino acids, and di- and tri-peptides can be determined from ileal fluid samples. Dietary influence on 
endogenous flow can be determined by feeding a nitrogen-free feed accompanied by an external marker.

\section{Apparent Digestion Techniques}

There are several methods of conducting a digestibility trial. Total fecal collection is the most accurate method of assessing nutrient digestibility and fecal output. This method requires animals' assimilation to the diet, then a period of several days to house the animal in a stall or collection crate and gather all fecal material. Total fecal collections are costly, require appropriate facilities to house the animals, and are often limited by labor, time, and equipment. This method may restrict the total number of subjects used in the experiment based on the aforementioned factors. Additionally, this method is impractical: for example, lactating mares, exercising horses, and animals intolerant to prolonged restraint or wear of collection harnesses are eliminated as candidates for this type of trial.

Internal and external markers can be used to estimate digestibility, intake of nutrients, and fecal output. Necessary qualifications for a marker include: mixture throughout the digesta, safe to ingest, non-absorbable and non-digestible. Internal markers are a natural part of the animal's diet; examples include acid insoluble ash (AIA), acid detergent insoluble ash (ADIA), and acid detergent lignin (ADL). These markers may be utilized when intake is unknown, such as in pasture-fed or group-housed animals. Intake can be estimated by collecting samples of feed and feces, and comparing the indigestible fraction of each. Digestibility can be calculated by comparing the difference in nutrient levels between feed and manure samples, relative to a known concentration of the internal marker. Common nutrients evaluated include: dry matter (DM), organic matter (OM), neutral detergent fiber (NDF), and acid detergent fiber (ADF). External markers are foreign supplements that are not naturally part of the diet in large 
quantities. Examples include chromic oxide $\left(\mathrm{Cr}_{3} \mathrm{O}_{2}\right)$ and titanium dioxide $\left(\mathrm{TiO}_{2}\right)$. Chromic oxide has been criticized for its use in animal digestibility studies because it cannot legally be incorporated into animal feed and also due to its carcinogenic properties in laboratory analysis (Delgarde et al., 2010). However, this risk can be mediated with modern laboratory analysis using induction-coupled plasma spectrometry (Sales et al., 2012).Also, this marker has also been shown to underestimate digestibility coefficients for DM values (Sales et al., 2012). Titgemeyer et al. (2001) utilized $\mathrm{TiO}_{2}$ in cattle for a digestibility trial, and found it underestimated total tract DM digestibility by 1.1-5.5\%. Using any external marker method for intake and digestibility estimation requires a consistent daily supplementation of the chosen marker. Fecal samples free from environmental contamination should be collected once the marker has had sufficient opportunity to assimilate throughout the digestive tract, usually requiring 7-10 days of adaptation (Owens and Hanson, 1992). Previous research has found a diurnal variation in the concentration of external markers (Titgemeyer et al., 2001). To compensate for this, fecal samples should be obtained over 4 days, with twice daily collections spaced 12 hours apart. Each day of sampling the time should advance by 3 hours. For example, day 1: 12AM/12PM, day 2: 3AM/3PM, etc. Upon completion of the sampling period, fecal samples for each subject can be composited to equally represent a 24 hour period, accounting for any variability in the fecal marker concentration.

Sources of errors can arise from marker estimation techniques that makes comparison between studies difficult. For example, results obtained from ADL analysis can vary due to difference in composition and amount of lignin in a horse's diet, which is the indigestible component found in all forage. As a grazing crop ages, the cell walls thicken and the ratio of lignin increases. Therefore, even if a single species of forage is under evaluation, analysis of its 
digestibility must be obtained from the same cutting of hay to minimize confounding variables. A large source of error can arise from how the fecal samples are obtained prior to analysis. Rectal fecal grabs are the most sanitary method for obtaining samples. Should freshly voided fecal samples be obtained, it is critical that there is no environmental contamination of the sample. Regardless of the marker used, sufficient time should be provided for the supplemental marker to plateau the digestive tract. Winsco et al. (2013) used $\mathrm{TiO}_{2}$ to estimate dry matter intake (DMI) in group-housed pregnant mares and found realistic total DMI values from 2.1-2.5\% BW throughout the trial. This project did not validate the external marker, however, so it is unknown if the values obtained were under- or over-estimated. Visser (2010) used 4 ponies in a $4^{\times} 4$ Latin square design to test $\mathrm{TiO}_{2}$ as a digestibility marker with a variety of forage/concentrate diets, and determined a 97\% recovery rate for the marker. Overall, external markers can be used in place of a total fecal collection to alleviate some restrictions. However, this method is also subject to certain errors that can be avoided by performing a total fecal collection.

Concepts from digestibility and voluntary intake often interrelate. Equines' intake of feed is influenced by several factors, including phenotypic characteristics of the individual and composition of the feedstuff. The size of the animal's upper arcade directly relates to the volume of biomass consumed (Fleurance et al., 2009). Horses' grazing behavior is often concentrated in shorter regions of pasture with less mature forage when given the option (Menard et al., 2002). It was once hypothesized that this selective behavior was a natural instinct of the horse to avoid manure sites where grass was taller, and thus, protecting themselves from parasite infestation (Taylor, 1954). Recent speculation for this behavior suggests that horses attempt to optimize their voluntary intake of nutrients by selecting forage that is easier to digest, and therefore less developed (Fleurance et al., 2007). However, some results have indicated that horses may prefer 
grazing taller grass in order to maximize voluntary DMI (Edouard et al., 2009), regardless of preestablished parasite load (Fleurance et al., 2005). Horses have been observed engaging in grazing behavior on pasture for $52-71 \%$ of a 24 hour day (Ellis 2010), consuming 2.0-2.5\% of their BW on an as-fed basis (NRC, 2007). According to results obtained from grazing ponies, average intake over 3 hours is $0.8 \% \mathrm{BW}$, indicating that in a 12 hour period an equine may consume at least $3 \%$ of its BW in forage (Longland et al., 2011).

When equids are provided with ad libitum access to feed, their voluntary consumption rate typically averages $3 \% \mathrm{BW}$. When ponies were fed free-choice pelleted diets, they consumed a total daily intake of $2.9 \pm 0.41 \% \mathrm{BW}$ within $10 \pm 0.9$ individual meals (Ralston et al., 1979). In this study, ponies spend approximately $38 \%$ of each day eating. In another study, Ralston and Baile (1982) infused ponies with $2 \mathrm{~L}$ of water (control) or $300 \mathrm{~g}$ glucose dissolved in $2 \mathrm{~L}$ of water, intragastrically after a 4 hour fast. The researchers observed a delay in post-fast feeding by $113 \pm 65$ minutes in the glucose group, suggesting the glucose had an internal effect on metabolic intake regulation.

Type and maturity of roughage alters DMI. Nutritive value of a forage is determined by laboratory analysis of crude protein (CP), neutral detergent fiber (NDF), acid detergent fiber (ADF), and crude fiber (CF) content. On a dry-matter basis, NDF content, which is comprised of lignin, hemicellulose, and cellulose, may range from $33 \%$ in legume pasture to $77 \%$ in Tifton hay (NRC, 2007). Edouard and colleagues (2009) observed a relationship between increased DMI and decreased CP and DMD of the forage. Other research has developed prediction equations for voluntary DMI based on NDF\% in hay, suggesting a strong inverse relationship $\left(\mathrm{r}^{2}\right.$ $=0.50-0.68$ ) between the variables (Lawrence et al., 2001; Reinowski and Coleman, 2003; Dulphy et al., 1997). 


\section{Digestive Aids}

There are many commercially available supplements designed to improve forage digestion in horses and optimize health. These supplements, termed 'digestive aids' or 'fermentation aids', are usually prebiotics, probiotics, or a live yeast supplement (Coverdale, 2016). Prebiotics are intended to improve the animal's health by altering the gastrointestinal microbiome in favor of fiber fermentation and VFA formation. Probiotics are often colonies of beneficial bacteria introduced into the gastrointestinal tract to benefit the immune system. This is accomplished by 'competitive inhibition' of absorption between the introduced bacteria with pathogenic microbes already inhabiting the hindgut (Berg, 1998).

Gonçalves et al. (2002) analyzed multiple case studies and found diets composed of forage high in cellulose resulted in a higher incidence of impaction colics. From another study reviewing 2060 cases (1030 diagnosed colic and 1030 diagnosis other than colic) treated by veterinarians across the United States within one year, researchers discovered that horses were 9.8 times more likely to have colic if the forage component of their diet rapidly changed within the past 2 weeks (Cohen et al., 1999). Yeast additives, such as Saccharomyces cerevisiae have shown promising results in the horse by increasing digestibility of DM, NDF, and ADF in Bermudagrass hay (Morgan et al., 2007). Medina et al. (2002) also demonstrated that supplementing $S$. cerevisiae orally increased the live population of yeast in the equine large intestine, which limits the elevation of lactic acid, ammonia, and increased cecal acidity when horses were fed a high-starch diet.

Unfortunately, this field of research is limited in providing in sufficient evidence-based conclusions on the potential benefit of digestive aid supplements. One possible reason for this is the lack of regulation between the advertised label compared to the actual amount within the 
product. Ensuring sufficient quantities of the live/active supplement reach the hindgut after exposure to enzymatic digestion in the foregut presents another challenge. Overall, this field requires further study to better understand methods of intervention in optimizing the horse's hindgut health.

\section{Body Composition}

Body composition is one outward reflection of health status in the horse. A sufficient amount of muscle and adipose tissue is required to maintain normal physiological function. Muscle is responsible for coordinating movement and storing glycogen. Compared to humans, equines have the ability to store 50\% more glycogen in their skeletal muscle (Bergstrom et al. 1972; Pösö et al., 2008), a quality that has likely enabled the horse's survival in escaping danger. This large supply of glycogen also functions as a source of substrate for production of adenosine triphosphate (ATP), enabling the horse to excel athletically.

Fat-free mass tends to remain relatively consistent throughout a horse's life, but adiposity can change significantly (Cordero, 2013). Monitoring a horse's fat content and maintaining a healthy level is important for longevity and health within the animal. Obesity has been linked to pro-inflammatory conditions, which can be correlated to an increase in blood serum levels of Creactive protein, interleukin-6, and tumor necrosis factor- $\alpha$ (Das, 2001). Further analysis of blood hormone levels in the horse has discovered a relationship between reduced insulin sensitivity to higher BF\%, TNF-p, TNF- $\alpha$, and IL-1 (Vick et al., 2007). Overweight horses are prone to insulin resistance, as well as a higher incidence of laminitis.

When conducting a nutrition trial, change in BW and overall condition must be monitored to evaluate the feed's effect. Caution should be used when drawing conclusions about a change in weight with the horse. It is common for the body weight to fluctuate throughout the 
day by $5 \mathrm{~kg}$ due to factors such as feed and water intake or defecation and urination (Webb and Weaver, 1979). A horse's BCS is most readily assessed by using the Henneke scoring system. By palpating the horse's crest, withers, back, tail head, behind the shoulder, and over the rib cage, one can provide an approximate determination of the animal's fat coverage. Henneke et al. (1983) studied the effect BCS has on reproductive success in mares and developed a scoring system to communicate a horse's condition, in which 1 indicates severe undernourishment, 5-6 indicates ideal body condition, and 9 indicates extreme obesity. This system has been widely applied across multiple studies due to its ease of use and minimal training requirements. The subjective nature of BCS does have limitations. For example, breed, age, and sex of the animal affect fat deposition. There is unavoidable bias in score dependent on the individual determining the BCS, and distinguishing between fat and muscle based solely on tactile assessment is difficult.

Post-mortem assessment of true body composition in the horse has resulted in significant variation of muscle and fat content based on the age, breed, and condition of the animal at its time of death. Schrottenloher (1951) initially described the horse carcass to contain $2.73 \%$ adipose tissue, but he did not report what state the animals were in prior to dissection. Webb and Weaver (1979) obtained data from 12 horse dissections, and determined adipose tissue to comprise $5.06 \%$ of the horses' (age 1-14 years) live weights. These horses' conditions were classified as either thin, lean, good, and one as fat, with variability in fed or fasted state prior to euthanasia. Manual extraction of adipose tissue can result in a large error while estimating total $\mathrm{BF}$ because intramuscular fat remains unaccounted for using this method. Other post-mortem methods of assessment include proximate chemical analysis and near-infrared spectroscopy. 
Improving the topline musculature has recently been a large focus in the equine nutrition industry (Lamprecht et al., 2016). The horse's 'topline' refers to the trapezius muscle, latissimus dorsi, and longissimus dorsi, encompassing the entire area from the neck to the tail head. To optimize the horse's genetic potential for muscle development along this region, the nutritional requirements must be met first. Muscle growth and maintenance requires adequate protein intake to compensate for loss in the continual cycle of protein turnover. Amino acids serve as the building blocks for muscle deposition, and must be supplied in appropriate levels to be utilized. For example, lysine is classified as the first limiting amino acid, meaning that if there is not a sufficient amount of this amino acid, other amino acids present will not be fully utilized. Twenty-two amino acids are used in muscle deposition, and nearly half of them must be provided in the horse's diet to maintain condition (Frape, 2010; Lamprecht et al., 2016).

In beef cattle, ultrasonography measurements have been used extensively to predict the carcass quality of the animal. Greiner et al. (2003) determined correlation coefficients of 0.89 and 0.86 between ultrasound measures and carcass fat and LDA, respectively. Ultrasonography measurements of back fat thickness have also been used as a method to evaluate morphometric change in dairy cattle; previous research correlates $(r=0.91)$ a change in 1 unit of BCS $(1-5$ scale) equating to a $23 \mathrm{~kg}$ change in BW (Wittek and Fürll, 2002). In addition, Schroder and Staufenbiel (2006) determined that a $1 \mathrm{~mm}$ change in back fat thickness correlates with a $5 \mathrm{~kg}$ change in total body fat content. Furthermore, Perkins et al. (1992) found a 0.75 correlation coefficient between ultrasonic back fat measurement and actual carcass measures $(P \leq 0.01)$. Although significant work has been done in the cattle industry to utilize ultrasonography as an accurate method for assessing live morphometric quantifications, this tool is largely underutilized in equine research. 
Ultrasonography has offered an objective assessment of a horse's subcutaneous fat and muscle coverage. Westervelt and associates (1976) assessed fat thickness in a consistent location along $(\mathrm{n}=8)$ horses' rumps $(5 \mathrm{~cm}$ dorsal of the midpoint between the tuber coxae and tuber ischiadicum) then correlated this value with an estimate of total BF within the animal. This approximation has also been used in multiple studies due to its relatively easy determination and minimal invasiveness. A limitation to this method is the assumption that one region of adiposity can be used to predict total BF. Also, intramuscular fat is largely unaccounted for. Gentry et al. (2004) compared BCS with ultrasonic measurements in 12 horses at BCS 3.0-3.5 and 12 horses at BCS 8.0-9.0. Results from this study indicated that correlation between BCS and rump fat was lower $(r=0.84)$ than correlations obtained using the tail head $(r=0.87)$ or withers $(r=0.86)$ regions.

\section{Deuterium Oxide}

Isotopic infusion is a useful method for evaluating morphometric characteristics in live animals. Common isotopes used to assess body composition are deuterium oxide $\left(\mathrm{D}_{2} \mathrm{O}\right)$, known as 'heavy water', and tritium oxide, known as 'super heavy water'. These isotopes are relatively safe to introduce into the subject, and are effective because they evenly distribute throughout an entire physiological system. When a known amount of the isotope is injected into a subject, analysis of plasma via mass spectrometry can estimate the total body water in the animal. Andrews et al. (1997) tested $\mathrm{D}_{2} \mathrm{O}$ in 6 healthy horses and determined there to be a 4 hour plateau phase from 3 to 7 hour post-injection. These researchers also measured a dose of $0.14 \mathrm{~g} \bullet \mathrm{kg}$ $\mathrm{D}_{2} \mathrm{O}^{-1} \bullet \mathrm{BW}^{-1}$, finding an average TBW (total body water) content of 63\%. Dugdale et al. (2011) validated this technique in ponies (BCS 1.25-7/9) by comparing values obtained from deuterium oxide analysis with post-mortem proximate analysis of tissue obtained from dissection. A similar 
experiment was performed in mature stock-type horses (Ferjak et al., 2017), and confirmed its usefulness for live-assessment of body composition. The Dugdale (2011) study found all measures of $\mathrm{D}_{2} \mathrm{O}$ were within $5 \%$ of the values obtained via proximate analysis of post-mortem tissues, thereby suggesting the strength of $\mathrm{D}_{2} \mathrm{O}$ as a method for live tissue analysis.

\section{Conclusion}

In summary, health and performance in the horse is a primary concern of for equine owners and managers. Providing a diet that optimizes maintenance of lean muscle and fat coverage is critical for horses at all life stages. Horse owners must contend with variability in the forage they can obtain for their animals, which may compromise the quality of nutrition, intake, and digestibility. By fortifying the concentrate diet with appropriate levels of amino acids, deficiencies may be addressed so that the horse's overall nutritional profile will be enhanced. In order to accurately assess change in a horse's body composition, and thus, well-being, several methods may be used. Although body condition scoring is convenient, its results are highly subjective and do not reflect changes in body tissue beyond tactile assessment. Ultrasonography and deuterium oxide infusion are alternative and more objective methods that can provide horse owners with a validated and accurate understanding of their horse's health. 


\section{CHAPTER II}

\section{MATERIALS AND METHODS}

The experimental protocol was approved by the Institutional Animal Care and Use Committee at Texas A\&M University (AUP\# 2016-0304).

\section{Horses and Dietary Treatments}

Twenty-three mature stock-type mares (422 to $583 \mathrm{~kg} \mathrm{BW}$ and 5 to $20 \mathrm{yr}$ of age) were used in a completely randomized design for a $56 \mathrm{~d}$ trial. Horses were stratified by bodyweight (BW), age, and body condition score (BCS) and assigned within strata across two dietary treatments. Treatments consisted of either a control diet $(\mathrm{CON}, \mathrm{n}=13)$ offered at $0.75 \% \mathrm{BW}$ daily, formulated to meet or exceed nutritional requirements for mature horses at maintenance (NRC, 2007) or the same pelleted concentrate (FORT; $n=10)$ includeding an additional amino acid fortification pack, fermentation metabolite additives, and complexed trace minerals. Dietary treatments were formulated to be isocaloric and isonitrogenous (Table 1; Table 2). Horses had ad libitum access to round bales of coastal Bermudagrass (Cynodon dactylon) hay. Every $14 \mathrm{~d}, \mathrm{BW}$ was recorded and intake adjusted accordingly. Investigators were blinded to dietary treatment. 
Table 1. Energy and nutrient composition of pelleted concentrate and coastal Bermuda grass (Cynodon dactylon) hay fed to stock-type mares.

\begin{tabular}{lccc}
\hline \hline \multicolumn{1}{c}{ Item $^{1}$} & \multicolumn{2}{c}{ Concentrate $^{2}$} & Hay \\
\hline & CON & FORT & \\
\hline DM, \% & 93.40 & 92.90 & 94.90 \\
Energy and nutrient (DM basis) & & & \\
NDF, \% & 41.50 & 40.70 & 77.50 \\
ADF, \% & 20.20 & 21.10 & 46.00 \\
ADIA, \% & 1.57 & 1.95 & 3.55 \\
Starch $^{3}, \%$ & 11.50 & 10.80 & 0.68 \\
DE $^{4}$, Mcal/kg & 2.76 & 2.79 & 1.85 \\
\hline
\end{tabular}

${ }^{1}$ Determined from laboratory analyses conducted at Texas A\&M University.

${ }^{2}$ Concentrate consisted of a either a control (CON) pellet or the same pelleted concentrate fortified (FORT) with an additional amino acid pack, fermentation metabolite additives, and complexed trace minerals concentrate that was offered at $0.75 \% \mathrm{BW}$ (as-fed basis).

${ }^{3}$ Values were obtained from laboratory analyses conducted at a commercial feed testing laboratory (SDK Laboratories, Hutchinson, KS).

${ }^{4}$ Calculated from equations in NRC (2007). 
Table 2. Amino acid composition of the control (CON) pellet and fortified (FORT) pellet that contained an additional amino acid pack, fermentation metabolite additives, and complexed trace minerals concentrate offered at $0.75 \% \mathrm{BW}$ (as-fed basis).

\begin{tabular}{lcc}
\hline \hline Item $(\mathrm{W} / \mathrm{W} \%)^{1}$ & CON & FORT \\
\hline Glutamic Acid & 2.22 & 2.14 \\
Aspartic Acid & 1.25 & 1.20 \\
Leucine & 1.08 & 1.07 \\
Proline & 0.88 & 0.86 \\
Arginine & 0.83 & 0.79 \\
Alanine & 0.74 & 0.73 \\
Glycine & 0.73 & 0.71 \\
Valine & 0.72 & 0.70 \\
Lysine & 0.68 & 1.02 \\
Phenylalanine & 0.64 & 0.62 \\
Serine & 0.56 & 0.53 \\
Isoleucine & 0.56 & 0.54 \\
Threonine & 0.52 & 0.53 \\
Tyrosine & 0.41 & 0.40 \\
Histidine & 0.36 & 0.35 \\
Cysteine & 0.27 & 0.25 \\
Methionine & 0.24 & 0.33 \\
Tryptophan & 0.15 & 0.13 \\
Hydroxyproline & 0.14 & 0.14 \\
Lanthionine $\S$ & 0.08 & 0.09 \\
Taurine $\S$ & 0.07 & 0.07 \\
Hydroxylysine & 0.03 & 0.03 \\
Ornithine $\S$ & 0.01 & 0.01 \\
\hline Total & $\mathbf{1 3 . 1 7}$ & $\mathbf{1 3 . 2 4}$ \\
\hline
\end{tabular}

$\left.{ }^{11} \mathrm{~W} / \mathrm{W} \%\right)$ indicates percent mass of item per $100 \mathrm{~g}$ of solution.

\section{Animal Performance}

Mares were evaluated every $14 \mathrm{~d}$ BW and BCS and on d 0,28, and 56 for fat thickness (FT), muscle depth (MD), and intramuscular fat (IMF) over the longissimus dorsi area (LDA) using ultrasonography. The musculoskeletal probe was fitted with a contoured pad and corn oil was applied to the ultrasound site to maximize echogenicity and minimize image artifacts.

Measurements included the intercostal space between the $13^{\text {th }} / 14^{\text {th }}$ ribs and the $17^{\text {th }} / 18^{\text {th }}$ ribs, and 
MD and FT over the rump. All FT and MD measurements were taken with the transduceroriented perpendicular to the horse's spine. Estimates of IMF of the LD muscle were determined by capturing four independent images over the $17^{\text {th }} / 18^{\text {th }}$ ribs with the transducer positioned parallel to the horse's spine. In accordance with Westervelt's method (1976), BF percentage was estimated from an equation using rump FT and MD measurements taken $5 \mathrm{~cm}$ from the midline and centered between the tuber coxae and tuber ischiadicum $(\% \mathrm{BF}=4.70 \times$ fat depth $(\mathrm{cm})+$ 8.64). All ultrasound measurements were obtained and interpreted by a single certified technician blind to treatments (Designer Genes Technologies, Inc., AR).

\section{Body Composition}

On d 0 and d 56 of the trial, horses underwent a deuterium oxide (Aldrich Chemistry, 99.9\% atom) infusion. On the morning of the D2O infusion, BW was measured on a digital platform scale, and a jugular intravenous catheter was placed and secured with adhesive bandaging tape. The jugular catheter site was prepared by clipping the coat to a sanitary length (blade size 40), and sterilized using Chloradine scrub 4\% in addition to isopropyl alcohol $70 \%$. Lidocaine was used as a local anesthetic and injected subcutaneously at the site of catheter insertion. At baseline, a venous catheter (12 g, Angiocath) and $30 \mathrm{~cm}$ extension set were inserted into the jugular vein under aseptic conditions and two $10 \mathrm{~mL}$ blood samples were obtained (Lithium Heparin 15 ml BD Vacutainer, 158 U.S.P. units). Horses were infused with an individual dose of deuterium oxide $\left(\mathrm{D}_{2} \mathrm{O} ; 0.12 \mathrm{~g} / \mathrm{kg} \mathrm{BW}\right)$ over a time period of 60 seconds, followed by a $100 \mathrm{~mL}$ saline flush to ensure all $\mathrm{D}_{2} \mathrm{O}$ was delivered. The dose of $\mathrm{D}_{2} \mathrm{O}$ was obtained from previous studies validating the method in the horse (Dugdale et al., 2011; Ferjak et al., 2017). Feed and water were withheld during the $4 \mathrm{~h} \mathrm{D}_{2} \mathrm{O}$ equilibration period. At post $4 \mathrm{~h}$ of infusion, two $10 \mathrm{~mL}$ blood samples were obtained contralateral to the site of catheter insertion. 
All blood samples were stored on ice then centrifuged at $2000^{\times} \mathrm{g}$ for $12 \mathrm{~min}$. Plasma was aliquoted and immediately stored at $-80{ }^{\circ} \mathrm{C}$ in $2 \mathrm{~mL}$ air-tight tubes (VWR, $2 \mathrm{~mL}$ micro-centrifuge tubes). Samples were analyzed by a commercial laboratory (Stable Isotopes Lab, University of Arkansas). In brief, plasma samples were thawed then filtered prior to analysis in triplicate by gas isotope ratio mass spectrometry. Samples underwent zinc reduction of the isotope-marked water. The deuterium abundance in the plasma samples was determined relative to a reference standardized tap water which had been normalized against the internal standards. Subsequent values were used to calculate the subject's total BF with a $4 \%$ correction factor to account for the exchange of non-water related hydrogen atoms within the body. A body lean hydration factor of 0.732 was used (Speakman, 1997). The following calculations will be used to estimate TBW, BF, and FFM:

$$
\begin{aligned}
& \text { Corrected } \mathrm{BWa}(\mathrm{kg})=\mathrm{BW} / 1.04 \\
& \% \mathrm{TBW}=\mathrm{BWa} / \mathrm{BW} \\
& \% \mathrm{BF}=100-(\% \mathrm{TBW} / 0.732) \\
& \% \mathrm{FFM}=\% \mathrm{TBW} / 0.732
\end{aligned}
$$

\section{Digestibility}

Nutrient digestibility was assessed through the use of internal (ADIA) and external (Titanium IV Dioxide, rutile; Sigma Aldrich) markers. On d 27 baseline fecal samples were collected. From d 28 to $41,5 \mathrm{~g}$ of titanium dioxide $\left(\mathrm{TiO}_{2}\right)$ was mixed and top-dressed onto each concentrate meal. After horses were supplemented with the external marker for $10 \mathrm{~d}$, feces were collected from d 38 to 41 of the study. To account for diurnal variation of composition, feces were collected twice daily at $12 \mathrm{~h}$ intervals and advanced by $3 \mathrm{~h}$ each subsequent day, which resulted in 8 fecal samples per mare over a $4 \mathrm{~d}$ collection period. A 200 to $400 \mathrm{~g}$ sample of feces was stored at $-20^{\circ} \mathrm{C}$ for later analysis. 
To prepare samples for analysis, feces, hay, and grain were dried in a forced air oven at $55^{\circ} \mathrm{C}$ for $96 \mathrm{~h}$ and allowed to equilibrate to room temperature for $24 \mathrm{~h}$. All samples were weighed before and after the drying process to determine partial dry matter (DM) percentage. Samples were ground in a Wiley mill to pass through a $1 \mathrm{~mm}$ screen. To determine overall DM percentage, samples were exposed to a $105^{\circ} \mathrm{C}$ drying oven for $24 \mathrm{~h}$. Similarly, to determine organic matter $(\mathrm{OM})$ percentage, difference in samples weight was measured prior and after exposure to a combustion oven at $450{ }^{\circ} \mathrm{C}$ for $8 \mathrm{~h}$. Neutral detergent fiber (NDF) and acid detergent fiber (ADF) values were determined by the Ankom Fiber Analyzer with sodium sulfite and $\alpha$ - amylase admitted and without correction for residual ash (Ankom Technology Corp., Macedon, NY). A Parr 6300 Calorimeter (Parr Instrument Company, Moline, IL) was used to measure gross heat energy (GE) for hay, grain, and fecal samples.

Forage consumption was estimated by $\mathrm{TiO}_{2}$ analysis following a previously established protocol (Myers et al., 2004). Concentrate, hay, and fecal samples were ashed at $450^{\circ} \mathrm{C}$ for $12 \mathrm{~h}$ then exposed to concentrated sulfuric acid (95-98\% w/w) for $2 \mathrm{~h}$ prior to the addition of $30 \%$ hydrogen peroxide solution. Samples were digested at $350^{\circ} \mathrm{C}$ for $45 \mathrm{~min}$ in a SCP digester. Absorbance at $410 \mathrm{~nm}$ was measured and compared to standards of $10,8,6,4$, or $2 \mathrm{mg} \mathrm{TiO}_{2}$ per $50 \mathrm{~g}$ solution. The following calculation was used to determine the concentration of $\mathrm{TiO}_{2}$ in each sample: $\mathrm{mg} \mathrm{TiO}_{2} / \mathrm{g}=\left(\mathrm{mg} \mathrm{TiO}{ }_{2}\right.$ sample $/ \mathrm{g}$ sample $)-\left(\mathrm{mg} \mathrm{TiO}_{2}\right.$ baseline $/ \mathrm{g}$ sample $)$.

\section{Statistical Analysis}

Intake, digestion, D2O, and performance variables were analyzed using the MIXED procedure (SAS Inst. Inc., Cary, NC). The model contained an effect of treatment and horse within diet included as a random effect. Correlations were determined using the PROC CORR procedure in SAS for BCS and body fat percentages determined by either a prediction equation 
(Westervelt et al., 1976) or deuterium oxide infusion. Main effects were considered significant when $P \leq 0.05$ and a trend toward significance when $P \leq 0.10$. 


\section{CHAPTER III}

\section{RESULTS}

\section{Intake and Performance}

In situations where both DMI and fecal output are not known, such as in the current group-housed setting, dual-marker systems may be used to estimate intake (Winsco et al., 2013). There was no affect of dietary treatment on total DMI $(P=0.41)$, with mares on the CON diet consuming $2.86 \% \mathrm{BW}$ compared to $2.74 \% \mathrm{BW}$ in mares supplemented with the FORT concentrate (Table 3). Concentrate DMI, when expressed as a percentage of BW, was not affected $(P=0.24)$ by dietary treatment. Similarly, dietary treatment did not affect hay DMI, with CON and FORT horses consuming $2.13 \%$ and $2.03 \% \mathrm{BW}$, respectively. Using measures of nutritive value and calculations based on the NRC (2007), the CON and FORT concentrates were calculated to contain 2.76 and $2.79 \mathrm{Mcal} / \mathrm{kg}$, and the hay contained $1.85 \mathrm{Mcal} / \mathrm{kg}$. Estimates based on the use of $\mathrm{TiO}_{2}$ in a dual marker system, CON mares consumed an average of 29.50 Mcal DE/d and FORT mares consumed 29.05 Mcal DE/d. Horses consumed an average of 638.5 and $654.6 \mathrm{~g} \mathrm{CP}$ and 21.32 and $31.97 \mathrm{~g}$ Lys per $\mathrm{d}$ from the CON and FORT concentrates, respectively (Table 3). According to NRC (2007) estimation of nutrient composition values in coastal Bermudagrass hay, horses consumed a maximum of $0.36 \mathrm{~g}$ Lys $/ \mathrm{kg}$, or an average of 4.46 $\mathrm{g}$ Lys and $4.44 \mathrm{~g}$ Lys for the CON and FORT diets, respectively. 
Table 3. Dry matter intake (DMI) of control (CON) or iso-caloric, iso-nitrogenous fortified (FORT) pelleted concentrate and coastal Bermudagrass (Cynodon dactylon) fed to stock-type mares (least square means).

\begin{tabular}{|c|c|c|c|c|}
\hline \multirow[b]{2}{*}{ Item } & \multicolumn{2}{|c|}{ Treatment $^{2}$} & \multirow[b]{2}{*}{ SEM } & \multirow[b]{2}{*}{$P$-value ${ }^{3}$} \\
\hline & $\mathrm{CON}$ & FORT & & \\
\hline Intake, \% BW & & & & \\
\hline DMI Grain & 0.73 & 0.71 & 0.01 & 0.24 \\
\hline DMI Hay ${ }^{1}$ & 2.13 & 2.03 & 0.03 & 0.54 \\
\hline DMI Total & 2.86 & 2.74 & 0.04 & 0.41 \\
\hline
\end{tabular}

${ }^{1}$ Hay intake determined using a dual-marker system with $\mathrm{TiO}_{2}$ as the external marker and ADIA as the internal marker (Titgemeyer et al., 2012).

${ }^{2}$ Treatment consisted of either a control $(\mathrm{CON} ; \mathrm{n}=10)$ concentrate or the same pelleted concentrate fortified (FORT; $\mathrm{n}=12$ ) with an additional amino acid pack, fermentation metabolite additives, and complexed trace minerals concentrate that was offered at $0.75 \% \mathrm{BW}$ (as-fed basis). Values listed were obtained from horses within 1 standard deviation of the mean DMI $(\mathrm{n}=22)$.

${ }^{3}$ Main effect of dietary treatment.

When evaluating the change over the feeding period (d 56 minus the $\mathrm{d} 0$ measurement obtained at the beginning of the trial), BW and BCS were unaffected by dietary treatment $(P>$ 0.63). The LDA and FT over the $12 / 13$ ribs $(P \geq 0.74)$ and IMF $(P=0.57)$ were not affected by diet. Horses maintained on the FORT diet gained FT over the $17 / 18$ ribs $(P \leq 0.02)$ and tended to gain in LDA over the $17 / 18$ ribs from d 0 to 56 of the trial $(P \leq 0.09$; Table 4$)$. No differences in RF or BF estimation $\left(P=0.38\right.$ and $P=0.58$, respectively) were detected. Utilizing a $\mathrm{D}_{2} \mathrm{O}$ infusion, BF was not affected on $\mathrm{d} 56$ by diet fortification $(P \leq 0.58$; Table 5$)$. 
Table 4. Mean change of ultrasonography measurements ( \pm SEM) of fat thickness $(F T)$ and longissimus dorsi area (LDA) over the $12^{\text {th }} / 13^{\text {th }}$ and $17^{\text {th }} / 18^{\text {th }}$ ribs and intramuscular fat (IMF) in response to feeding either a CON or FORT pelleted concentrate and coastal Bermudagrass.

\begin{tabular}{|c|c|c|c|c|}
\hline \multirow[b]{2}{*}{ Variable } & \multicolumn{2}{|c|}{ Treatment $^{1}$} & \multirow[b]{2}{*}{ SEM } & \multirow[b]{2}{*}{$P$ - value ${ }^{2}$} \\
\hline & $\mathrm{CON}$ & FORT & & \\
\hline \multicolumn{5}{|c|}{ LDA 12th and 13th Rib, $\mathrm{cm}^{2}$} \\
\hline Initial & 72.07 & 69.89 & 2.71 & 0.55 \\
\hline Final & 77.28 & 73.32 & 2.71 & 0.35 \\
\hline Change & 5.21 & 3.43 & 2.84 & 0.74 \\
\hline \multicolumn{5}{|l|}{ FT 12th and 13th Rib, cm } \\
\hline Initial & 0.16 & 0.16 & 0.01 & 0.98 \\
\hline Final & 0.17 & 0.17 & 0.01 & 0.99 \\
\hline Change & 0.01 & 0.01 & 0.01 & 0.98 \\
\hline \multicolumn{5}{|l|}{ LDA 17 th and 18 th $\mathrm{Rib}, \mathrm{cm}^{2}$} \\
\hline Initial & 84.95 & 80.97 & 2.78 & 0.29 \\
\hline Final & 89.43 & 92.45 & 2.71 & 0.41 \\
\hline Change & $4.48^{\mathrm{a}}$ & $11.48^{\mathrm{b}}$ & 3.03 & 0.09 \\
\hline \multicolumn{5}{|l|}{ FT 17 th and 18th Rib, $\mathrm{cm}^{2}$} \\
\hline Initial & 0.25 & 0.27 & 0.03 & 0.67 \\
\hline Final & $0.28^{\mathrm{a}}$ & $0.41^{\mathrm{b}}$ & 0.03 & $\leq 0.01$ \\
\hline Change & $0.03^{\mathrm{a}}$ & $0.14^{b}$ & 0.03 & 0.02 \\
\hline \multicolumn{5}{|l|}{ Intramuscular Fat, $\%^{3}$} \\
\hline Initial & 3.92 & 4.07 & 0.16 & 0.47 \\
\hline Final & 3.13 & 3.45 & 0.23 & 0.37 \\
\hline Change & -0.79 & -0.62 & 0.22 & 0.57 \\
\hline
\end{tabular}

a,b Within item, means that do not have a common superscript differ by $(P \leq 0.10)$.

${ }^{1}$ Treatments consisted of a controlled $(\mathrm{CON})$ or fortified (FORT) pelleted concentrate offered at $0.75 \%$ BW (as-fed basis) and allowed ad libitum access to coastal Bermudagrass (Cynodon dactylon) hay.

${ }^{2}$ Main effect of dietary treatment.

${ }^{3}$ Intramuscular fat percentage measurements obtained on the left hip determined by capturing four independent images over the $17^{\text {th }} / 18^{\text {th }}$ ribs with the transducer positioned parallel to the horse's spine (Aloka SSD-500V, Aloka Inc., Tokyo, Japan). 
Table 5. Mean BW ( \pm SEM), BCS, and BF change in response to feeding either a CON or FORT pelleted concentrate and coastal Bermudagrass.

\begin{tabular}{|c|c|c|c|c|}
\hline \multirow[b]{2}{*}{ Variable } & \multicolumn{2}{|c|}{ Treatment $^{1}$} & \multirow[b]{2}{*}{ SEM } & \multirow[b]{2}{*}{$P$-value ${ }^{2}$} \\
\hline & $\mathrm{CON}$ & FORT & & \\
\hline \multicolumn{5}{|l|}{$\mathrm{BW}, \mathrm{kg}$} \\
\hline Initial & 494.35 & 500.01 & 12.74 & 0.74 \\
\hline Final & 505.44 & 508.34 & 13.54 & 0.87 \\
\hline Change & 11.09 & 8.33 & 4.32 & 0.63 \\
\hline \multicolumn{5}{|l|}{ Body Condition Score ${ }^{3}$} \\
\hline Initial & 5.60 & 5.57 & 0.27 & 0.92 \\
\hline Final & 5.74 & 5.78 & 0.29 & 0.92 \\
\hline Change & 0.14 & 0.21 & 0.15 & 0.72 \\
\hline \multicolumn{5}{|l|}{ Rump fat, $\mathrm{cm}^{4}$} \\
\hline Initial & 0.81 & 0.86 & 0.10 & 0.90 \\
\hline Final & 1.04 & 0.86 & 0.10 & 0.31 \\
\hline Change & 0.23 & 0.00 & 0.15 & 0.38 \\
\hline \multicolumn{5}{|l|}{ Body fat estimation ${ }^{5}, \%$} \\
\hline Initial & 12.65 & 12.55 & 0.59 & 0.90 \\
\hline Final & 12.74 & 13.51 & 0.57 & 0.31 \\
\hline Change & 0.09 & 0.96 & 0.72 & 0.38 \\
\hline \multicolumn{5}{|l|}{ Body fat estimation ${ }^{6}, \%$} \\
\hline Initial & 7.71 & 7.57 & 0.73 & 0.89 \\
\hline Final & 9.00 & 8.45 & 0.81 & 0.62 \\
\hline Change & 1.29 & 0.88 & 0.56 & 0.58 \\
\hline
\end{tabular}

${ }^{1}$ Treatments consisted of a controlled (CON) or fortified (FORT) pelleted concentrate offered at $0.75 \% \mathrm{BW}$ (as-fed basis) and allowed ad libitum access to coastal Bermudagrass (Cynodon dactylon) hay.

${ }^{2}$ Main effect of dietary treatment.

${ }^{3}$ Average of 3 evaluators using a 1 to 9 scoring system (Henneke et al., 1983).

${ }^{4}$ Rump fat measurements obtained on the left hip at a point $5 \mathrm{~cm}$ dorsal of half way between the first coccygeal vertebrae and the ischium (Westervelt et al., 1976) using an ultrasound instrument (Aloka SSD-500V, Aloka Inc., Tokyo, Japan).

${ }^{5}$ Body fat estimated by using prediction equation, $\%$ body fat $=4.70 \times$ fat depth $(\mathrm{cm})+8.64$ (Westervelt et al., 1976).

${ }^{6}$ Body fat estimated by using $0.12 \mathrm{~g} / \mathrm{kg} \mathrm{BW}$ of deuterium oxide.

\section{Apparent Digestion}

All digestibility coefficients were calculated based on total tract apparent digestibility. Average starch digestibility coefficients were similar, 0.98 and 0.96 , for horses receiving the CON or FORT diets, respectively $(P=0.16$; Table 6$)$. Values for ADF and NDF did not differ $(P$ 
$\geq 0.93)$ between dietary treatments. Similarly, DM and OM were not affected by $\operatorname{diet}(P \geq 0.96)$.

Despite the addition of fermentation aids in the FORT diet, apparent digestion did not differ between treatments.

Table 6. Apparent digestion of nutrients in response to feeding either a CON or FORT pelleted concentrate and coastal Bermudagrass.

\begin{tabular}{lllll}
\hline & \multicolumn{3}{c}{ Treatment $^{1}$} & \\
\cline { 2 - 3 } Item & CON & FORT & SEM & $P$-value $^{2}$ \\
\cline { 1 - 3 } Apparent Digestion, \% & & & & \\
DM & 0.67 & 0.65 & 0.04 & 0.96 \\
Starch & 0.98 & 0.96 & 0.01 & 0.16 \\
NDF & 0.66 & 0.63 & 0.06 & 0.95 \\
ADF & 0.61 & 0.58 & 0.06 & 0.93 \\
GE Digestibility & 0.69 & 0.68 & 0.02 & 0.71 \\
\hline Treatments consisted of a controlled (CON) or fortified (FORT) pelleted concentrate offered at \\
0.75\% BW (as-fed basis) and allowed ad libitum access to coastal Bermudagrass (Cynodon \\
dactylon) hay. \\
${ }^{2}$ Main effect of dietary treatment.
\end{tabular}




\section{CHAPTER IV}

\section{DISCUSSION}

\section{Intake and Digestibility}

In the current study, BW and BCS of horses were not affected by $56 \mathrm{~d}$ of diet fortification. Lucia et al. (2014) observed a similar response in a group of mature sedentary horses housed in similar climatic conditions, which were fed a fortified diet (complexed trace minerals, pre- and pro-biotics, enhanced amino acids, and elevated vitamin E) or a non-fortified control diet. Increases in BW and BCS were observed over the $154 \mathrm{~d}$ study; however, similar to the current study, these variables were not affected by diet. Lucia et al. (2014) observed specific ultrasonography measurements such as the LDA, and LDFT and RF increased in response to diet fortification $(P \leq 0.01)$. In the current study, the posterior segment of the horses' topline, over the $17^{\text {th }}$ and $18^{\text {th }}$ ribs, responded to dietary fortification.

Mares fed the fortified concentrate, which included nearly twice the Lys content as the control $(\mathrm{CON}=0.68 ; \mathrm{FORT}=1.02)$, tended have a greater LDA in response to diet fortification, although the other areas of the topline were unaffected. Throughout the trial, mean LDA over the $17 / 18$ ribs ranged from 81.0 to $92.6 \mathrm{~cm}^{2}$, comparatively larger than the same measurement over the $12^{\text {th }}$ and $13^{\text {th }}$ ribs, which measured 69.0 to $73.9 \mathrm{~cm}^{2}$. Miller et al. (2017) reported similar measures in mature Quarter horses ( $\mathrm{n}=10 ; 2-6$ yrs.) when compared to the current study. For instance, the LDA over the $17^{\text {th }}$ and $18^{\text {th }}$ ribs ranged from 90.0 to $106.9 \mathrm{~cm}^{2}$, and over the $12^{\text {th }}$ and $13^{\text {th }}$ ribs ranged from 77 to $92 \mathrm{~cm}^{2}$. On a similar size comparison, steers have relatable ultrasonography measurements compared to horses. In 1965, Hedrick et al. assessed the LDA in good and choice steer carcasses of various weights. Those in the weight class closest to mature horses weighed a minimum of $386 \mathrm{~kg}$, and averaged an LDA of $81.4 \mathrm{~cm}^{2}$. 
Lysine is the only amino acid with an established dietary requirement in the horse (NRC, 2007). With the exception of Lys, CON and FORT diets were not different in amino acid composition. If amino acid requirements are not met for a species, then protein synthesis resulting in muscle deposition will not occur (Mastellar et al., 2016). According to NRC (2007) recommendations, a $500 \mathrm{~kg}$ horse at maintenance should receive $27 \mathrm{~g}$ Lys $/ \mathrm{d}$ to meet requirements. It is possible that due to the lower quantity of $\mathrm{CP}$ in the hay, horses fed CON (Lys $25 \mathrm{~g} / \mathrm{d}$ ) were not adequately supplied with lysine compared to horses fed FORT (Lys $35 \mathrm{~g} / \mathrm{d}$ ) concentrate, and thus did not experience muscle development over this area of the topline. Therefore, one limitation in the current study is that it is unclear if the greater 17/18 LDA measures in the FORT horses were due to dietary fortification alone.

Based on prior research that estimates the pre-cecal digestion of coastal Bermudagrass to be 37\% (Gibbs et al., 1988), the average digestible Lys intake from forage consumed by CON and FORT horses was calculated to be $1.41 \mathrm{~g}$ and $1.37 \mathrm{~g}$, respectively. Pre-cecal digestion of protein and amino acids changes with diet composition (de Almeida et al., 1998a; de Almeida et al., 1998b; van Niekerk and van Niekerk, 1997), and the values calculated are likely an overestimation because the $\mathrm{CP}$ of hay in the present study was significantly lower (8 vs. $10 \%)$. Additionally, differences in other region of the horses' toplines may not have been detected in the current study due to the short duration. Winsco et al. (2011) assessed growth measurements and rump fat over $56 \mathrm{~d}$ in weanling horses receiving 1 of 4 isonitrogenous diets with varying Met concentrations. The researchers did not observe a difference between treatments in BW or rump fat throughout the trial in horses undergoing rapid growth. Lucia et al. (2014) began to observe changes in rump fat at d 56 in mature horses supplemented with a similar fortified diet. In one 
experiment involving ponies either fed $1.5 \% \mathrm{BW}$ or fed ad libitum, Westervelt et al. (1976) noted a significant difference between fat cover in the ponies after $126 \mathrm{~d}$.

In the current study, DMI of hay did not differ between diets. All horses were grouphoused in a dry lot and had access to a round bale. The dual marker system of $\mathrm{TiO}_{2}$ and $\mathrm{ADIA}$ indicated that there were no differences in the apparent digestion of starch, DM, OM, NDF, or ADF. In a previous study that performed a total fecal collection, horses supplemented for $28 \mathrm{~d}$ with a dehydrated yeast fermentation product tended to have greater apparent digestibility of NDF and ADF than the control group (Coverdale et al., 2013). The type of yeast supplemented to the horse can have a positive effect on digestibility of structural carbohydrates when the concentration of cellulolytic bacteria is increased. For example, when Saccharomyces cerevisiae is added to the diet, the equine's hindgut prevalence of lactate decreases, which reduces acidity and creates a more favorable environment for cellulolytic bacteria (Jouany et al., 2008).

In a recent study, Agazzi et al. (2011) fed horses a grass/legume mixed forage $(9.8 \% \mathrm{CP}$, 64.2\% NDF, and 46.2\% ADF) for two weeks, followed by $18 \mathrm{~d}$ of live yeast (S. cerevisiae) supplementation offered twice daily. No difference was observed in DMI $(P \geq 0.48)$; however, apparent digestion of DM, OM, NDF, and ADF increased $(P \leq 0.04)$ in supplemented horses compared to the control group and CP tended to improve $(P \leq 0.08)$. Morgan et al. $(2007)$ used a total fecal collection to assess the apparent digestibility of low-quality and high-quality hay fed to horses receiving a yeast culture supplement. Results from the study indicated that the highquality forage $(13.1 \% \mathrm{CP}, 73.1 \% \mathrm{NDF}, 35.3 \% \mathrm{ADF})$ was more digestible in every component than the low-quality forage $(8.1 \% \mathrm{CP}, 75.3 \% \mathrm{NDF}, 37.6 \% \mathrm{ADF})$. In addition, the yeast culture supplement increased the digestibility of NDF, hemicellulose, and CP. 


\section{Body Composition}

Using infusion of the stable isotope $\mathrm{D}_{2} \mathrm{O}$, total body water was quantitatively assessed in mature horses and subsequently percent BF was calculated for mares assigned to either the CON or FORT treatment diet. Percentage of BF increased over the $56 \mathrm{~d}$ across treatments; however, differences were not detected between dietary treatments.

Absence of change in percent $\mathrm{BF}$ relative to treatment correlates with no significant change observed in BW, BCS, or BF estimated from rump fat. In this experiment, percent BF $\left(\mathrm{D}_{2} \mathrm{O}\right)$ was $8.72 \%$ in mares with an average BCS of 5.58 and 5.76 on $\mathrm{d} 0$ and 56 , respectively. Dugdale et al. (2011) estimated BF using deuterium oxide at $13.1 \%$, in mature horses that were between a BCS of 1 to 7. Ferjak et al. (2017) estimated BF to be 5.99\% and $10.28 \%$ in horses with a BCS of 5 or 6 , respectively. The BF estimations were similar to values calculated in the current study in horses with a similar BCS, which ranged from $7.57 \%$ to $9.00 \% \mathrm{BF}$, and further supports the use of deuterium oxide to evaluate live morphometrics in the horse.

When data sets were averaged across dietary treatments for BCS and BF according to both Westervelt and $\mathrm{D}_{2} \mathrm{O}$ evaluations, moderate positive correlations were seen. Deuterium oxide BF estimates were moderately correlated with BCS $(\mathrm{r}=0.51 ; P \leq 0.01)$, and correlated with the Westervelt BF estimate ( $\mathrm{r}=0.43 ; P \leq 0.01)$; additionally, the Westervelt BF estimate was moderately correlated with BCS $(\mathrm{r}=0.41 ; P \leq 0.01)$. This value indicates a lower correlation than other research conducted on stock-type horses undergoing moderate exercise, which found $\mathrm{r}$ $=0.50$ between RF and BCS (Pritchett et al., 2016). Prior research which compared these morphometric measurements with post-mortem fat assessment determined that deuterium oxide estimates are the optimal method of assessing actual body fat ( $\mathrm{r}=0.86$ to 0.98$)$ (Ferjak et al., 2017). The Westervelt equation is used to calculate percent $\mathrm{BF}$ is as follows: $\mathrm{BF}=8.64+$ 
4.70 $\times \mathrm{RF}(\mathrm{cm})$. Assuming that the horse measured had no rump fat, this equation would still estimate the total $\mathrm{BF}$ of the animal at $8.64 \%$. Thus, this equation can present a large source of error by estimating the horse's total BF based on one measured location, and may explain our low correlation value between the two variables calculating percent BF. 


\section{CHAPTER V}

\section{SUMMARY}

In summary, diet fortification has the potential to provide topline development in the horse. This project investigated tissue change through objective means in the mature sedentary horse and determined the region over the $17^{\text {th }} / 18^{\text {th }}$ ribs was the most sensitive to lean muscle and fat development. In the current study, analysis of $\mathrm{BF}$ using a $\mathrm{D}_{2} \mathrm{O}$ infusion allowed for a more precise quantification of the change in morphometric values throughout the trial. Supplying dietary prebiotics and probiotics when feeding low-quality forages did not significantly improve hindgut digestibility or nutrient utilization in the horses. 


\section{LITERATURE CITED}

Aiken, G. E., G. D. Potter, B. E. Conrad, and J. W. Evans. 1989. Voluntary intake and digestion of coastal bermuda grass hay by yearling and mature horses. J. of Eq. Vet. Sci. 9(5):262264. doi.org/10.1016/S0737-0806(89)80084-X

Agazzi, A., M. Ferroni, A. Fanellie, S. Maroccolo, G. Invernizzi, V. Dell'Orto, and G. Savoini. 2011. Evaluation of the Effects of Live Yeast Supplementation on Apparent Digestibility of High-Fiber Diet in Mature Horses Using the Acid Insoluble Ash Marker Modified Method. J. Eq. Vet. Sci. 31(1):13-18. doi.org/10.1016/j.jevs.2010.11.012

Batista-Gonzalez, A., E. Tarabra, M. Toledo, J. P. P. D. Barros, G. Tam, M. L. Aoun, E. Picarda, D. F. Riascos-Bernal, N. E. Sibinga, X. Zang, and K. K. Buhman. 2018. Lipid Activates mTORC1 and mTORC2 in the Absorption of Dietary Triglycerides. Available at SSRN 3245484.

Bergström, J., E. Hultman, and A. Roch-Norlund. 1972. Muscle Glycogen Synthetase in Normal Subjects: Basal Values, Effect of Glycogen Depletion by Exercise and of a CarbohydrateRich Diet Following Exercise. Scandinavian J. of Clin. Lab. Inv. 29(2):231-236. doi.org/10.3109/00365517209081080

Cohen, N., Gibbs, P., \& Woods, A. 1999. Dietary and other management factors associated with equine colic. In AAEP Proceedings. 44:96-98.

Coverdale, J. A. 2016. Horse species symposium: Can the microbiome of the horse be altered to improve digestion? J. Anim. Sci. 94:2275-2281. doi.org/10.2527/jas.2015-0056

Coverdale, J. A., E. D. Lamprecht, P. Kropp, I. Yoon, J. L. Lucia, K. N. Winsco, A. E. Hanson, and C. M. Warzecha. 2013. Influence of diet fortification on mature horses at maintenance: performance characteristics. J. Anim. Sci. 91(E-Suppl. 2):565. (Abstr.). 
de Almeida, F. Q., S. de Campos Valdares Filo, J. L. Donzele, J. F. C. da Silva, M. I. Leao, P. R. Cecon, and C. de Queiroz. 1998a. Apparent and true prececal and total digestibility of protein in diets with different protein levels in equines. R. Bras. Zootec. 27:521-529.

de Almeida, F. Q., S. de Campos Valdares Filo, J. L. Donzele, J. F. C. da Silva, M. I. Leao, P. R. Cecon, and C. de Queiroz. 1998b. Endogenous amino acid composition and true prececal apparent and true digestibility of amino acids in diets for equines. R. Bras. Zootec. 27:546-555.

De Fombelle, A., M. Varloud, A. Goachet, E. Jacotot, C. Philippeau, C. Drogoul, and V. Julliand. 2003. Characterization of the microbial and biochemical profile of the different segments of the digestive tract in horses given two distinct diets. Anim. Sci. 77(2):293304. doi.org/10.1017/S1357729800059038

Doreau, M., S. Boulot, D. Bauchart, J. P. Barlet, and W. Martin-Rosset. 1992. Voluntary intake, milk production and plasma metabolites in nursing mares fed two different diets. The J. of Nutr. 122(4):992-999.

Dugdale, A., G. Curtis, P. Harris, and C. M. Argo. 2011. Assessment of body fat in the pony: Part I. relationships between the anatomical distribution of adipose tissue, body composition and body condition. Eq. Vet. J. 43(5):552-561. doi.org/10.1111/j.20423306.2010.00330.x

Duncan, P., T. J. Foose, I. J. Gordon, G. C. Gakahu, and M. Lloyd. 1990. Comparative nutrient extraction from forages by grazing bovids and equids: a test of the nutritional model of equid/bovid competition and coexistence. Oecologia 84(3):411-418. 
Edouard N., G. Fleurance, B. Dumont, R. Baumont, and P. Duncan. 2009. Does sward height affect feeding patch choice and voluntary intake in horses?. App. Anim. Behav. Sci. 119(3-4):219-28. doi.org/10.1016/j.applanim.2009.03.017

Ferjak, E. N. 2017. Body fat determination of stock-type horses predicted by rump fat thickness and deuterium oxide dilution and validated by near-infrared spectroscopy of dissected tissues. J. Anim. Sci. 95(10):4344-4351. doi.org/10.2527/jas2017.1676

Fleurance, G., P. Duncan, H. Fritz, J. Cabaret and I. J. Gordon. 2005. Importance of nutritional and anti-parasite strategies in the foraging decisions of horses: an experimental test. Oikos. 110(3):602-612. doi.org/10.1111/j.0030-1299.2005.13428.x

Fleurance, G., Duncan, P., Fritz, H., Cabaret, J., Cortet, J., \& Gordon, I. J. 2007. Selection of feeding sites by horses at pasture: testing the anti-parasite theory. App. Anim. Behav. Sci. 108(3-4):288-301. doi.org/10.1016/j.applanim.2006.11.019

Fleurance, G., Fritz, H., Duncan, P., Gordon, I. J., Edouard, N., \& Vial, C. 2009. Instantaneous intake rate in horses of different body sizes: influence of sward biomass and fibrousness. App. Anim. Behav. Sci., 117(1-2):84-92. doi.org/10.1016/j.applanim.2008.11.006

Frape, D. Equine Nutrition and Feeding. $4^{\text {th }}$ ed, Wiley-Blackwell. Print.

Garlinghouse, S.E. and M. J. Burrill. 1999. Relationship of body condition score to completion rate during $160 \mathrm{~km}$ endurance races. Eq. Vet. J. 31(S30):591-595. doi.org/10.1111/j.2042-3306.1999.tb05290.x

Gibbs, P. G., G. D. Potter, G. T. Schelling, J. L. Kreider, and C. L. Boyd. 1988. Digestion of hay protein in different segments of the equine digestive tract. J. Anim. Sci. 66:400-406. doi.org/10.2527/jas1988.662400x 
Gonçalves, S., V. Julliand and A. Leblond. 2002. Risk factors associated with colic in horses. Vet. Res. 33(6):641-652. doi.org/10.1051/vetres:2002044

Hamer, H. M., D. Jonkers, K. Venema, S. Vanhoutvin, F. J. Troost, and R. Brummer. 2008. The role of butyrate on colonic function. Alimentary Pharm. \& Ther. 27(2):104-119. doi.org/10.1111/j.1365-2036.2007.03562.x

Hedrick, H. B., J. C. Miller, G. B Thompson, and R. R. Freitag. 1965. Factors affecting longissimus dorsi area and fat thickness in beef and relation between these measurements and retail yield. J. Anim. Sci 24(2):333-337. doi.org/10.2527/jas1965.242333x

Henneke, D., G. Potter, J. Kreider, and B. Yeates. 1983. Relationship between condition score, physical measurements and body fat percentage in mares. Eq. Vet. J. 15(4):371-372. doi.org/10.1111/j.2042-3306.1983.tb01826.x

Hintz, H.F., R. A. Argenzio, H. F. Schryver. 1971. Digestion Coefficients, Blood Glucose Levels and Molar Percentage of Volatile Acids in Intestinal Fluid of Ponies Fed Varying ForageGrain Ratios. J. of Anim. Sci. 33(5):992-995. doi.org/10.2527/jas1971.335992x

Hoffman, R. M. 2013. Carbohydrates. Equine Applied and Clinical Nutrition. Print. p. 156-167.

Jouany, J. P., J. Gobert, B. Medina, G. Bertin, and V. Julliand. 2008. Effect of live yeast culture supplementation on apparent digestibility and rate of passage in horses fed a high-fiber or high-starch diet. J. Anim. Sci. 86:339-347. doi.org/10.2527/jas.2006-796

Lamprecht, E., R. Mueller, and A. Keegan. 2016. Equine topline: Nutrition at the core. NutrenaCargill Inc.

Leturque, A., E. Brot-Laroce, and M. Le Gall. 2009. GLUT2 mutations, translocation, and receptor function in diet sugar managing. Am. J. Phys. 296(5):E985-E992. 
Lucia, J. L., E. D. Lamprecht, M. J. Anderson, K. J. Stutts, M. M. Beverly. S. F. Kelley, and D. L. Parker. 2014. Influence of diet fortification on mature horses at maintenance: performance characteristics. J. Anim. Sci. 92(E-Suppl. 2):194. (Abstr.).

Mastellar, S., R. Coleman, K. Urschel. 2016. Controlled trial of whole body protein synthesis and plasma amino acid concentrations in yearling horses fed graded amounts of lysine. The Vet. J. 216:93-100. doi.org/10.1016/j.tvj1.2016.07.007

Medina, B., I. D. Girard, E. Jacotot, and V. Julliand. 2002. Effect of a preparation of Saccharomyces cerevisiae on microbial profiles and fermentation patterns in the large intestine of horses fed a high fiber or a high starch diet, J. Anim. Sci. 80(10):2600-2609. doi.org/10.1093/ansci/80.10.2600

Menard, C., P. Duncan, G. Fleurance, J. Y. Georges, \& M. Lila. 2002. Comparative foraging and nutrition of horses and cattle in European wetlands. Journal of App. Ecol. 39(1):120-133. doi.org/10.1046/j.1365-2664.2002.00693.x

Miller, E. F. 2017. The effect of CLA supplementation on fat deposition and lean muscle mass in horses. Sam Houston State University. (Doctoral dissertation).

Morgan, L., J. Coverdale, M. Froetschel, and I. Yoon. 2007. Effect of yeast culture supplementation on digestibility of varying forage quality in mature horses. J. of Equine Vet. Sci. 27(6):260-265. doi.org/10.1016/j.jevs.2007.04.009

Myers, W. D., P. A. Ludden, V. Nayigihugu, and B. W. Hess. 2004. Technical note: A procedure for the preparation and quantitative analysis of samples for titanium dioxide. J. Anim. Sci. 82:179-183. doi.org/10.2527/2004.821179x

NRC. 2007. Nutrient requirements of horses. $6^{\text {th }}$ rev. ed. Natl. Acad. Press, Washington, DC. 
Orton, R. K., I. D. Hume, and R. A. Leng. 1985. Effects of exercise and level of dietary protein on digestive function in horses. Eq. Vet. J. 17(5):386-390. doi.org/10.1111/j.20423306.1985.tb02530.x

Pösö, A., H. Seppo, and R. Geor. 2008. Metabolic responses to exercise and training. Equine Exercise Physiology: The Science of Exercise in the Athletic Horse. Elseviers Limited. Online.

Pritchett, K. B., J. L. Leatherwood, K. J. Stutts, and M. J. Anderson. 2016. Use of ultrasonography to evaluate the accuracy of objective and subjective measures of body composition in horses. J. Anim. Sci. 94(1):16. doi.org/10.2527/ssasas2015-033

Ralston, S.L., G. Van den Broek and C. A. Baile. 1979. Feed intake patterns and associated blood glucose, free fatty acid and insulin changes in ponies. J. Anim. Sci. 49(3):838-845. doi.org/10.2527/jas1979.493838x

Ralston, S. L. and C. A. Baile. 1982. Gastrointestinal stimuli in the control of feed intake in ponies. J. Anim. Sci. 55(2):243-253. doi.org/10.2527/jas1982.552243x

Sales, J. 2012. A review on the use of indigestible dietary markers to determine total tract apparent digestibility of nutrients in horses. Anim. Feed. Sci. and Tech. 174(3-4):119130. doi.org/10.1016/j.anifeedsci.2012.03.005

Swyers, K.L., A. O. Burk, T. G. Hartsock, E. M. Ungerfeld, and J. L. Shelton. 2008. Effects of direct-fed microbial supplementation on digestibility and fermentation end-products in horses fed low-and high-starch concentrates. J. Anim. Sci. 86(10):2596-2608. doi.org/10.2527/jas.2007-0608

Taylor, E. L. 1954. Grazing behaviour and helminthic disease. Brit. J. of Anim. Behav. 2(2):6162. 
Titgemeyer, E. C., C. K. Armendariz, D. J. Bindel, R. H. Greenwood, and C. A. Löest. 2001. Evaluation of titanium dioxide as a digestibility marker for cattle. Am. Soc. Anim. Sci. 79(4):1059-1063. doi.org/10.2527/2001.7941059x

van Niekerk, F. E. and C. H. van Niekerk. 1997. The effect of dietary protein on reproduction in the mare. I. The composition and evaluation of the digestibility of dietary protein from different sources. J. S. Afr. Vet. Assoc. 68:78-80.

Vick, M.M., A. A. Adams, B. A. Murphy., D. R. Sessions, D. W. Horohov, R. F. Cook., B. J. Shelton and B. P. Fitzgerald. 2007. Relationships among inflammatory cytokines, obesity, and insulin sensitivity in the horse. J. Anim. Sci. 85(5):1144-1155. doi.org/10.2527/jas.2006-673

Webb, A. I. and B. M. Weaver. 1979. Body composition of the horse. Eq. Vet. J. 11(1):39-47. Westervelt, R., J. Stouffer, H. Hintz, and H. Schryver. 1976. Estimating fatness in horses and ponies. J. Anim. Sci. 43(4):781-785. doi.org/10.2527/jas1976.434781x

Winsco, K. N., J. A. Coverdale, T. A. Wickersham, and J. L. Shelton. 2011. Influence of dietary methionine concentration on growth and nitrogen balance in weanling Quarter Horses. J. Anim. Sci. 89(7):2132-2138. 